\title{
Using a Case Study to Teach Leaders How to Enact Positive Organizational Change
}

\begin{abstract}
It can be difficult for students to digest and learn complex theories of organizational culture and change without being able apply the steps to a real or imagined scenario. Oftentimes, they lack experience and can't imagine the components of each phase or step without a practical example. This article discusses the theoretical background of leading positive organizational change and then uses a case study to help students apply their knowledge. It highlights the fictional leadership dilemma of a young Army officer, First Lieutenant Jordan Baker, upon arrival to her new duty location. Instructors can use the case to teach the 4-Phase Leading Change Framework which incorporates Kotter's eight-step model to enact positive change. The purpose of this case is to give instructors a framework to teach students in a stepwise fashion, making concepts easier for students to visualize.
\end{abstract}

\section{Introduction}

Teaching organizational culture and change at the United States Military Academy can be challenging, especially when training young, inexperienced cadets. These future military leaders are better able to understand the steps within an organizational change framework when they can apply it to a case in a stepwise fashion. Furthermore, using small groups within the classroom can help students brainstorm, share ideas, and internalize concepts within the framework more easily. This paper uses a leader dilemma to help describe a method for teaching organizational culture and change. Although the case is fictional, it is based on a composite of leadership experiences and interactions of an Army officer.

The case describes the situation of a new Army officerin-charge (OIC) of a military troop medical clinic (TMC).
Upon arriving to her new duty location, the OIC injures herself and seeks medical care from the medical clinic she will soon lead. The OIC's first experience with the medical clinic is negative. The clinic's policies and staff behaviors are focused on internal efficiency and not compassionate patient care. The OIC realizes that the organizational culture must change. She has a challenge ahead that may require significant effort to positively change the organization's culture.

The case highlights how a leader who is new to an organization can assess the extant culture, identify any issues, and then design a method for implementing change in that culture. It utilizes the 4-phase Leading Change Framework which incorporates Kotter's 8-step model to ultimately enact positive and needed change within an organization.

The paper will first introduce the theoretical background of organizational culture and change to 
include an overview of the 4-phase Leading Change Framework. Next, the case will be presented. Finally, a teaching strategy will be introduced for a 75-minute lesson incorporating the 4-phase Leading Change Framework as discussed in the theoretical background.

\section{Theoretical Foundation}

It is sometimes necessary to change culture to achieve a certain goal or transform a negative climate. Leading organizational change is perhaps the most complex requirement facing today's leaders. It is what separates leadership from management (Spain, LeBeouf, \& Cook, 2018). Research indicates that nearly 70 percent of change initiatives fail (Hughes, 2011). Part of this failure is because 29 percent of change initiatives begin without a formal plan (Blanchard, 2010), and the other part of this failure can be attributed to leadership style or a leadership style mismatch (Kotter, 2000; Appelbaum, Degbe, MacDonald, \& Nguyen-Quang, 2015; Nging, \& Yazdanifard, 2015). To enact successful change, a structured series of phases or steps is recommended. Kotter (1995) suggests eight steps for leaders who want to successfully transform their businesses. For the purposes of this case, we utilize the 4-phase Leading Change Framework which incorporates Kotter's 8-step model as depicted in Figure 1. These steps are composed of the growing body of research focused on organizational culture and leading positive change. Toward that end, Moran and Brightman (2001) highlight the need to focus on individuals impacted by the change and reduce their anxiety by clearly communicating the nature, timing, and specifics of the changes they will encounter. Nelissen and Martine (2008) underscore that argument by suggesting communication strategies that will assuage employee anxieties.

\section{LCF Phase 1: Assess the Need for Change}

Artifacts, Espoused Beliefs \& Values, Basic Underlying Assumption

LCF Phase 2: Identify Resistance and Prepare for Change

Individual-, team, and organizational-level analysis

1. Establish a Sense of Urgency (Kotter Step 1)

2. Form a Powerful Guiding Coalition (Kotter Step 2)

3. Create a Vision (Kotter Step 3)

\section{LCF Phase 3: Lead Change}

4. Communicate the Vision (Kotter Step 4)

5. Empower Others to Act on the Vision (Kotter Step 5)

6. Plan for and Create Short-Term Wins (Kotter Step 6)

7. Consolidate Improvements and Produce More Change (Kotter Step 7)

LCF Phase 4: Anchoring the Change into the Culture

Schein's Embedding and Reinforcing Mechanisms

8. Anchor New Approached into the Culture (Kotter Step 8)

Figure 1: 4-Phase Leading Change Framework incorporating Kotter's 8-step model (Spain, LeBeouf \& Cook, 2018; Kotter 1995). 
The first phase of the 4-phase Leading Change Framework is to assess the need for change. This includes identifying three levels at which culture manifests itself: observable artifacts, espoused beliefs and values, and basic underlying assumptions (Schein, 1990). Artifacts include things that people can see, hear, and feel across an organization such as: common phrases or topics of conversation, confrontations, arrangement of physical space, systems in place, access to leaders, work habits, how people treat each other, and posters on the wall (Spain, LeBeouf \& Cook, 2018). Espoused beliefs and values are gathered through interviews and discussions with employees (Schein, 1990). Examples of espoused beliefs and values include statements of organizational goals, how leaders claim the organization behaves, vision statements, and customer service mottos. Finally, basic underlying assumptions are the values-in-use by an organization (Spain, LeBeouf \& Cook, 2018). The need for change can be assessed by comparing the artifacts, espoused beliefs and values, and basic underlying assumptions by an organization. If an organization's artifacts, espoused beliefs, and basic underlying assumptions are congruent, then the organizational culture is likely functional. If there are inconsistencies between what is claimed and observed, then the organizational culture is likely dysfunctional, and positive change should occur.

The second phase of the 4-phase Leading Change Framework is to identify resistance and prepare for change. First, the leader must identify any individuallevel, team-level, and organizational-level resistance to change as outlined in Table 1 (Spain, LeBeouf, \& Cook, 2018). Next, the leader must establish a sense of urgency (Kotter Step 1), form a powerful guiding coalition (Kotter Step 2), and create a vision (Kotter Step 3). Establishing a sense of urgency is often thought of as the most difficult step, but also the most important. It includes identifying potential or actual crises to help overcome organizational complacency (Spain, LeBeouf, \& Cook, 2018). To form a powerful guiding coalition, the leader must assemble a group that both works well together as a team and is powerful enough to lead the change effort (Kotter, 1995). Finally, the vision should paint a clear picture of what the guiding coalition envisions for the future. This should include setting a goal that is specific, challenging, achievable and time-limited (Spain, LeBeouf, \& Cook, 2018).

Table 1: Leading Change Framework phase two- Identifying resistance to change (individual, team and organizational level) (Spain, LeBeouf, \& Cook, 2018).

\begin{tabular}{|l|l|}
\hline \multicolumn{2}{|c|}{ Resistance to Change } \\
\hline Individual-Level & $\begin{array}{l}\text { past negative experiences with change; lack of resources or skills needed; loss of } \\
\text { influence over the team or situation; threatens routines; implies inadequacy; fear } \\
\text { of not being able to keep up; feeling like he or she are not needed; fear of being } \\
\text { used during the change }\end{array}$ \\
\hline Team-Level & threatens patterns of behavior; challenges friendships and previous teams \\
\hline Organizational-Level & $\begin{array}{l}\text { threatens current systems and traditions in place; limited resources; nature of a } \\
\text { bureaucracy to resist change }\end{array}$ \\
\hline
\end{tabular}


The third phase of the 4-phase Leading Change Framework is to lead change and includes steps four through eight of Kotter's 8-step model as depicted in Figure 1. It picks up where phase two left off with communicating the vision (Kotter Step 4). To achieve this step, leaders must use a multitude of communication methods. Face-to face meetings, formal and informal gatherings, training platforms, posters, memorandums, and electronic media are just a few examples. Leaders should also remember that the example they set is often as important as what they say about their vision. Therefore, the guiding coalition must always be willing and able to set the example for the organization (Kotter, 1995). In his 1995 article, Leading Change: Why Transformation Efforts Fail, Kotter says, "If you can't communicate the vision to someone in five minutes or less and get a reaction that signifies both understanding and interest, you are not done." Leaders must not only ensure that the vision is motivational and easy to understand, but they also must encourage others to act on the vision (Kotter Step 5). This includes reducing or eliminating barriers to change (including bureaucracy), creating incentives, and recognizing people that support the organization's new vision. It is during this phase that leaders should begin implementing both embedding and reinforcing mechanisms (Kotter, 1995), and continue implementing them during the third phase.

The third phase also includes planning for and creating short-term wins (Kotter Step 6) and consolidating improvements and producing more change (Kotter Step 7). Creating short-term wins is an effective way to keep members of the organization motivated and focused on the vision. People want to see that the vision is good for the organization and short-term achievements can create an avalanche of momentum towards the larger goal (Spain, LeBeouf, \& Cook,
2018). Creating short-term wins can also involve recognizing employees that have made an impact in enacting change. One pitfall of Kotter's seventh step is to declare success too soon, therefore consolidating improvements and producing more change is often the longest and most time-consuming step of the 4-phase Leading Change Framework (Spain, LeBeouf, \& Cook, 2018).

The fourth phase of the 4-phase Leading Change Framework is anchoring the change into the culture and is strongly influenced by Kotter's final process, anchoring new approaches into the culture (Kotter Step 8). The most important aspect of this step is to achieve internalization of the vision (Spain, LeBeouf, \& Cook, 2018). Kotter (1995) says that, "Until new behaviors are rooted in social norms and shared values, they are subject to degradation as soon as the pressure for change is removed." A good way to assess if the values and culture are being internalized is to again identify the artifacts, espoused beliefs and values, and basic underlying assumptions. Internalization can be confirmed if there is harmony along these domains. Furthermore, an organization has truly internalized a changed organizational culture if the culture persists once a leader has left the organization or the guiding coalition has disbanded (Spain, LeBeouf, \& Cook, 2018).

As an alternative to Kotter's 8-step model, Schein's five embedding mechanisms are a method to change a culture and his five reinforcing mechanisms are ways to anchor it- both depicted in Table 2 (Schein, 1985). Though his embedding mechanisms align primarily with phase 3 , and his reinforcing mechanisms with phase 4 , both groups of mechanisms are useful in phases 2 through 4 of the Leading Change Framework (Spain, LeBeouf \& Cook, 2018). 
Table 2: Schein's Embedding and Reinforcing Mechanisms (Spain, LeBeouf \& Cook, 2018; Schein, 1990).

\begin{tabular}{|l|l|}
\hline Schein's Embedding Mechanisms & Schein's Reinforcing Mechanisms \\
\hline How the leader responds to critical events & Organizational stories about its legacy \\
\hline What the leader notices, measures, and manages & Organizational structure \\
\hline How the leader sets the example & Organizational office layout \\
\hline $\begin{array}{l}\text { How the organization attracts, selects, and retains } \\
\text { team members }\end{array}$ & Organizational policies and procedures \\
\hline What the leader rewards and punishes & Statements about organizational values and philosophies \\
\hline
\end{tabular}

Effectiveness of this Learning Activity. The effectiveness of this learning activity is manifest in three ways. First, the students not only learn seminal scholarship in the leading organizational change literature, but they also can apply it in a realistic scenario. The second way this learning activity is effective is that students get immediate feedback on their analysis of the case's symptoms and root causes, as well as the leader action plans, they devise to address those symptoms and causes. The third way this learning activity is effective is by creating the conditions for students to learn from each other as they discuss the case in class. Understanding is further verified by exam results, as well as testimonials of cadets who enact these lessons in their cadet companies, where they initiate a specific change to either policies or procedures with the Corps of Cadets, and then lead that change through to its implementation. Once implemented, cadets measure the success and adjust if the change initiative initially fails. Cadets get "real world" feedback from their units, as well as coaching and feedback on their change efforts from their tactical officers. This is a powerful learning event because it allows cadets to put theory into practice with immediate opportunity for expert feedback. In a military education setting, the case study allows us to bridge the gap between education and training. According to Christensen, Garvin, and Sweet (1991), creating the conditions for deep reflection and practical application improves the learning of and mastery of concepts, which in turn improves reasoned judgment.

Student Learning Outcomes. There are four objectives of this learning activity. The first is to provide students with the theoretical foundation and facility to analyze an organization's broad and specific symptoms by describing "what is going on" and "what is NOT going on". The second learning objective is to provide students an opportunity to apply organizational theory to ascertain the potential causes of the symptoms they have identified. In this phase, they articulate "why" things are happening and NOT happing. The third learning objective is to provide students an opportunity to determine the underlying drivers (root causes) of the issues 
identified in the case study. The fourth learning objective is to provide students with the opportunity to address each of the issues in a wholistic manner by parsimoniously applying the concepts they have learned about leading change.

\section{Case: Troop Medical Clinic (TMC)}

U.S. Army First Lieutenant (1LT) [1] Jordan Baker is a Medical Service Corps (MSC) officer. Her bosses thought highly of her and recently nominated her as a candidate for the position of officer-in-charge (OIC) [2] of one of the post's troop medical clinics (TMCs). She was scheduled to take over the following Monday. 1 LT Baker's earlier research told her that the TMC she was headed to consisted of two physician assistants and fifteen medics. Running it would be a huge step up in responsibility for her, but she felt like she was up to it.

When 1LT Baker called the clinic's departing OIC, he had great things to say about the TMC's operation. He enthusiastically told 1LT Baker about how professional the "docs" were, and how the TMC had the most up-to-date equipment available. He seemed pleased to tell her how the TMC worked like a team and that according to a recent inspection by the higher-level command, the quality of care at the TMC was twice as good as it was last year.

Despite his optimistic assessment of the TMC, $1 \mathrm{LT}$ Baker had heard conflicting views. A friend of hers told her that most of the soldiers disliked going to the clinic. According to her friend, he and several of his soldiers wait until the weekends to go to the hospital emergency room or pay out of pocket to go to a civilian clinic to avoid the hassle of the TMC.

During a morning run the Friday before 1LT Baker was scheduled to take over, she stepped in a small pothole and twisted her ankle. When she got up, she saw the words "Sustain the Fighting Force" emblazoned on a sign and realized that she was in front of her future TMC. Hobbling with pain, she made her way to the entrance.

At the door, 1LT Baker got in line behind a dozen soldiers in camouflage uniform, the duty uniform. They all seemed to be waiting to report to a medic sitting at a table in the foyer. After 20 minutes, she finally arrived in front of the medic.

"Name, rank, and unit," he asked. 1LT Baker responded. As the young soldier filled out a form, he pointed to a sign. The sign said, "A failure to plan ahead on your part does not constitute an emergency on mine." 1LT Baker did not understand what this had to do with anything, so she asked what the point was. He then pointed to another sign that stated the uniform for sick call was the duty uniform, not physical training (PT) uniform. 1LT Baker quickly explained her mishap and nearly begged to get an exception to the policy. The medic finally relented and asked to see 1LT Baker's sick call slip [3] as he took her blood pressure and temperature. After explaining why she did not have a sick call slip, the medic condescendingly said, "I guess you think you are above the rules." 1LT Baker had to bite her tongue because she just wanted to be seen by the doctor. He then had her write her name, date, and the time in a well-worn ledger and handed her the patient information sheet that he had filled out. He told her to follow the yellow footsteps painted on the ground to get to the administrative medic located behind the first set of partitions.

1LT Baker followed the footsteps as they zigzagged in between partitions. As she limped, she felt like a rat in a maze. She arrived in a waiting room occupied by ten other soldiers. Six were seated, but the others were waiting for a chair. 1LT Baker stood in front of the administrative medic who was busy entering data into a computer. The wall behind her was covered with certificates, at least two of them for improving the data management system. Without removing her eyes from the screen she said, "Put your records in the box marked 'records,' sign the book, take a seat, and wait for your name to be called." "I don't have my records," 1LT Baker told her. The administrative (admin) medic glanced up from the screen, noticed 
1LT Baker was in a PT uniform, and asked if she knew the uniform policy.

The admin medic listened while her eyes remained glued to the screen. She typed something into her computer and said, "According to our files, you never turned your records back in after your last physical, as required. After more negotiations, 1LT Baker managed to convince the medic to make an exception and agree for her to be seen. 1LT Baker then slid her way over to the waiting area and spent the next 20 minutes watching her ankle grow and listening to her stomach growl.

"Hey, what do you guys do for breakfast?" she asked a soldier who was also waiting. "Breakfast? Who can get breakfast when you must sign out for sick call at 0530 and come over here immediately to get in this line?" a soldier responded. "Most times someone comes in here, he or she will be here until at least 0900."

After 45 minutes, 1LT Baker's name was called. The examination room was brightly lit, and the stainless steel of the new looking medical equipment accentuated the spotless quality of the room. Hanging on the walls were several posters proclaiming the virtues of "Motivation" and "Teamwork." Additionally, she saw a framed paragraph entitled "Our Values," which said, "We are committed to patient-oriented service and quality of care."

The physician assistant (PA) finally entered, and for the third time this morning, 1LT Baker retold her story. She also mentioned that she was looking forward to being the OIC. "Well," he said, "we have some of the best medics I've seen in my 16 years of service, and for once we actually have enough of them. We finally got a system where we can give high quality care and not get bogged down with the whiners just trying to get a profile because a field problem is coming up." As he carefully wrapped her ankle, 1LT Baker asked him to elaborate on these "whiners." He went on, "About six months ago, we noticed that right before every field problem, physical test, or major inspection, we have a heavy influx of sick call. Most of their problems were the kind you can't see like stomach problems or headaches. The best idea came from one of our young soldiers. See this block on your patient info sheet?" 1LT Baker nodded. "If the screening medic writes 'SK' here, that means that the soldier is shirking or just trying to get over. If I see that, I give him or her a profile for a day, but nothing longer." The PA wrote out a prescription for some painkillers, gave her a three-day profile avoiding exercise of the lower extremities, and asked her to continue to follow the yellow footsteps down the hallway.

As 1LT Baker followed the yellow footsteps, she stopped by the pharmacy to get her prescription filled. She signed her name in a book, filled out a slip of paper, and inserted it in a slot in the window. Ten minutes later, she received a small container with a three-day supply of painkillers. "Hey, wait a minute," she called through a tiny hole in the window, "I'm going to need more than three days' worth of these things." A firm voice came back through the slot, "Sorry, we only give out three days of meds to maintain accountability and to make sure the system isn't abused. These are narcotics, you know. If you need more, just sign back in on sick call and we'll give you another prescription. Have a nice day," the voice added.

As $1 \mathrm{LT}$ Baker limped out of the TMC, she realized that it was already 0930. In three short days, that TMC would be hers.

The following Monday, 1LT Baker arrived to the TMC by 0510 . Since sick call would not start for a few more minutes, she gathered all the TMC staff and introduced herself as the new OIC. Several of them looked uncomfortable after she told them she was the officer who came in on Friday in the PT uniform with the twisted ankle. She let them know that her experience as a patient last week was unpleasant, and from what she had heard and seen, some things needed to change at the TMC. Specifically, she shared "My intent for this organization is for us to really care, to really do what our motto says: 'Sustain the Fighting Force,' and live by the framed 'TMC Values: Accessibility, Efficiency, Excellent Patient Care' hanging in one of the exam rooms. From now on, 
we need to treat our patients with respect and put their needs before our own. Does anybody have any questions or suggestions?" No one said anything.

Later that morning, 1LT Baker was visited by Master Sergeant (MSG) Grimaldi, the clinic's NonCommissioned Officer-in-Charge (NCOIC). In a quiet, professional voice he said, "Ma'am, in the future, when you want to change our operations, I sure wish you'd consult me first. We'd all like to do the best thing, but why would you want to change an operation that has been getting kudos from all the brass? This crew is outstanding and the most efficient team I've seen."

A week later, 1LT Baker was sitting in her office when the phone rang. It was her boss informing her that the Department of the Army Inspector General would be sending a team to inspect the TMC the following month. Their focus was going to be on quality of care measured, at least in part, by customer satisfaction.

Perhaps 1LT Baker underestimated the difficulty of squaring away the TMC.

Note:

1. Rank Explanation:

a. First Lieutenant (1LT): Falls within the officer ranks, it generally takes 24 months to achieve this rank once commissioned as an officer. Officers are senior in rank to warrant officer and enlisted ranks, to include a master sergeant and a Physician's Assistant (typically a warrant officer).

b. Master Sergeant (MSG): A senior noncommissioned officer (NCO), it generally takes $15-20$ years in the Army to achieve this rank.

2. The Officer-in-Charge (OIC) is the director of the medical clinic and oversees all operations and personnel at the clinic. The Non-Commissioned Officer-in-Charge (NCOIC) is the assistant director of the medical clinic. He has direct influence over the enlisted personnel (medics) within the organization.
3. A sick call slip is paperwork that gives a soldier permission to seek medical care from the TMC and therefore miss work.

\section{Teaching Strategy Preparation}

Students should read the TMC case prior to arriving to class. Other suggested readings can be found in the following resources and can be assigned as reading if so desired:

Kerr, S. (1975). On the folly of rewarding A, while hoping for B. Academy of Management Journal, 18(4), 769-783.

Kotter, J. (2007). Leading change: Why transformation efforts fail. Harvard Business Review, 86, 97-103.

Moran, J. W., \& Brightman, B. K. (2001). Leading organizational change. Career development international, 6(2), 111-119.

Nelissen, P., \& Van Selm, M. (2008). Surviving organizational change: how management communication helps balance mixed feelings. Corporate Communications, 13(3), 306-318. http://dx.doi.org.usmalibrary.idm.oclc. org/10.1108/13563280810893670

Schein, E. H. (1990). Organizational culture: What it is and how to change it. Human resource management in international firms, 56-82.

Spain, Everett, LeBeouf, Joseph, \& Cook, Chaveso. (2018). A Leader's Guide to Assessing Organizational Culture and Leading Positive Change. In Smith, Swain, Brazil, Cornwell, Britt, Bond, Eslinger, and Eljdid (Eds.), West Point leadership. New York, NY: Rowan Technology Solutions. 


\section{Teaching Strategy for a 75-minute class}

Each part of the teaching strategy is divided into one of the four phases of the Leading Change Framework. Instructors should break students down into groups to discuss each phase and then discuss the answers to the questions as a class.

\section{Summary of the Case (5 minutes)}

1. Have a student summarize the case.

\section{Leading Change Framework Phase 1: Assess the Need for Change (20 minutes)}

2. Break students down into their groups for five minutes to discuss the following questions:

- What is the current problem with operations at the TMC?

- Identify the organization's culture by identifying current artifacts, espoused beliefs and values, and underlying assumptions.

- Is the current organizational culture functional or dysfunctional and why?

- What are the goals and expectations of the TMC? Is there an official charter for them?

- How are the expectations and values of the TMC communicated to its personnel and patients?

- What are other indicators of needs for change?

3. Gather students back together to lead a discussion.

- Current Problems: staff's attitudes toward patients'(poor); general customer care (poor)

- Artifacts: poster on the wall that says, "A failure to plan ahead on your part does not constitute an emergency on mine"; other posters on the wall that say "motivation" and "teamwork"; the way the office space is arranged (yellow, zigzagging footsteps on the floor between office partitions; not enough chairs in the waiting room; wall behind Admin medic covered in certificates of appreciation); systems in place (signing out for sick call before 0530; writing SK on info sheet; not dispensing enough medication needed for the patient); treatment of patient by TMC staff (medic giving the 1LT a hard time upon admission for her uniform and paperwork; Admin medic not using direct eye contact; Admin medic arguing with a patient that is injured)

- Espoused Values: "Sustain the fighting force"; what other people within the organization have said to the new $1 \mathrm{LT}$ about the TMC to include:

- Departing OIC: "docs" are professional, and he was proud of how the TMC had the most up-to-date equipment available in the Army system; TMC worked like a team and that a recent inspection by the leadership identified the quality of care at the TMC was twice as good as last year.

- Physician's Assistant (PA): the best medics and enough of them; a system where they can give high quality care and not get bogged down with the whiners.

- MSG Grimaldi (Clinic NCOIC): the operation at the TMC had been getting kudos from the brass and the team was outstanding and efficient; they worked well together.

- Basic Underlying Assumptions: the duty of the team is to identify people who are trying to get out of duties (SK=Shirkers); the team values state-of-the art equipment and cleanliness; the team values external 
(chain of command) approval and achievements; values efficiency of systems and throughput

- Functional or Dysfunctional: the organization is dysfunctional due to the incongruence between the artifacts, espoused beliefs and values, and the basic underlying assumptions.

- Other indicators or need for change: soldiers dislike going to the TMC and would rather go the hospital ER or pay out of pocket to go to a civilian clinic; the Department of the Army Inspector General is sending a team to inspect next month, and the focus will be quality of care measured in part by customer satisfaction.

\section{Leading Change Framework Phase 2: Identify Resistance and Prepare for Change (15 minutes)}

4. Break students down into their groups for five minutes to discuss the following questions:

- Identify individual-level, team-level, and organizational-level resistance to change.

- (Kotter Step 1): How will you establish a sense of urgency?

- (Kotter Step 2): Ask students the following questions:

- How will you form a powerful guiding coalition?

- What are the interdependencies across the organization and its command that might require coordination?

- Who will help you create change within the organization?

- How will you approach this person to help you?

- What will you say or do to get support?
- (Kotter Step 3): What is your vision for the organization?

5. Gather students back together to lead a discussion.

\section{- Resistance to Change}

- Individual-Level: threatens routines (team feels like they have a good system already in place); loss of influence over the team or situation (soldiers feel like they have input into the systems that are in place); implies inadequacy (taking away the systems that are already in place may make people feel like their input is not needed)

- Team-Level: challenges friendships and previous teams (the group felt like they were working well as a team, including key players such as the PA and MSG Grimaldi); threatens patterns of behavior (the basic underlying assumptions can also be seen as the groups norms; they will need to re-focus the group norms to focus on patient care and customer satisfaction)

- Organizational-Level: limited resources (time); bureaucracy inherently resistant to change (military hierarchy that had already given the TMC kudos for their systems and performance)

Establishing a sense of urgency: You can use the Inspector General visit next month as a reason to start change now with a new focus on customer satisfaction and patient care.

Forming a powerful guiding coalition: MSG Grimaldi (Clinic NCO) will be essential to have as a lead member of your guiding coalition. Other key members include the PA.

Vision for the organization: "My intent for this organization is for us to really care, to really do what our motto says, 'Sustain the Fighting Force."' The focus should be on patient care, quality, speed, and customer satisfaction; treat everyone with respect. 
Ensure the vision is specific, challenging, achievable and time limited.

Leading Change Framework Phase 3: Lead Change (15 minutes)

6. Break students down into their groups for five minutes to discuss the following questions:

- (Kotter Step 4): How will you communicate your vision to your staff and customers? How will you get the word out on the base?

- (Kotter Step 5): How will you empower others to act on the vision?

- (Kotter Step 6): What are some short-term wins that you could achieve to show the team that this change is a good thing?

7. Gather students back together to lead a discussion.

- Communication of Vision: communication of vision to staff(training meetings, e-mail, briefings); communication of vision to patients (social media, newspaper/public affairs, flyers, briefing of base commander/other leadership on base, removal of negative artifacts and replacement with positive artifacts that are congruent with new vision)

- Empower others to act on vision: incentives for staff (based on percentage increase of customer satisfaction numbers); read positive comment cards during staff meetings; expand job descriptions of staff members to empower them

- Short-Term Wins: seeing a change in customer satisfaction numbers and positive comments; performance on the pending Inspector General inspection

Leading Change Framework Phase 4: Anchoring Change into the Culture (15 minutes)
8. Break students down into their groups for five minutes to discuss the following questions:

Schein's Embedding Mechanisms: What type of embedding mechanisms will you use to anchor change at the TMC? Which might work the best for this type of organization? How will you measure and demonstrate success?

Schein's Reinforcing Mechanisms: What type of reinforcing mechanisms will you use to anchor change at the TMC?

9. Gather students back together to lead a discussion.

- Schein's Embedding Mechanisms: what the leader notices, measures, and manages (OIC's constant presence and positive example at the $\mathrm{TMC}$ ); how the leader sets the example (OIC's constant presence and positive example at the TMC; re-enforcement that patient care, customer satisfaction and treating patients with dignity and respect is very important)

- Schein's Reinforcing Mechanisms: organizational office layout (re-design the way customer experience upon entry into the TMC, as they currently feel like a rat in a maze); statements about organizational values and philosophies (treating patients with dignity and respect); organizational policies and procedures (re-thinking the SK and pharmacy policy, as well as other policies that negatively impact the patient experience).

\section{Summary and Lesson Wrap-Up (5 minutes)}

10. Summarize the discussion and provide students with 2-3 takeaways from the case study. 


\section{References}

Appelbaum, S. H., Degbe, M. C., MacDonald, O., \& Nguyen-Quang, T. S. (2015). Organizational outcomes of leadership style and resistance to change (Part One). Industrial and Commercial Training.

Blanchard, K. (2010). Mastering the Art of Change-Ken Blanchard offers some strategies for successfully leading change. Training Journal, 44.

Christensen, C.R., Garvin, D.A., \& Sweet, A. (Eds.). (1991). Education for Judgment: The Artistry of Discussion Leadership. Boston: Harvard Business School Press.

Duening, T. N. (Ed.). (2016). Leading the positive organization: Actions, tools, and processes. ProQuest Ebook Central https://ebookcentral.proquest.com

Hughes, Mark. “Do 70 Per Cent of All Organizational Change Initiatives Really Fail?” Journal of change management 11.4 (2011): 451-464. doi.org/10.1080/14697017.2011.630506

Kerr, S. (1975). On the folly of rewarding A, while hoping for B. Academy of Management Journal, 18(4), 769783.

Kotter, J.P. (2000) "What Leaders Really Do", The Bottom Line, Vol. 13 No. 1. https://doi.org/10.1108/ bl.2000.17013aae.001

Kotter, J. (2007). Leading change: Why transformation efforts fail. Harvard Business Review, 86, 97-103.

Moran, J. W., \& Brightman, B. K. (2001). Leading organizational change. Career development international, $6(2), 111-119$.

Nelissen, P., \& Martine, v. S. (2008). Surviving organizational change: how management communication helps balance mixed feelings. Corporate Communications, 13(3), 306-318. http://dx.doi.org.usmalibrary. idm.oclc.org/10.1108/13563280810893670

Nging, T. K., \& Yazdanifard, R. (2015). The general review of how different leadership

styles cause the transformational change efforts to be successful. International Journal of Management, Accounting and Economics, 2(9), 1130-1140.

Schein, E. H. (1985). The Jossey-Bass management series and The Jossey-Bass social and behavioral science series. Organizational culture and leadership: A dynamic view.

Schein, E. H. (1990). Organizational culture: What it is and how to change it. Human resource management in international firms, 56-82.

Schein, E. H. (1991). What is culture. Newbury Park: Sage, 313.

Spain, Everett, LeBeouf, Joseph, \& Cook, Chaveso. (2018). A Leader's Guide to Assessing Organizational Culture and Leading Positive Change. In Smith, Swain, Brazil, Cornwell, Britt, Bond, Eslinger, and Eljdid (Eds.), West Point leadership. Rowan Technology Solutions. 